\title{
Acceptability of opportunistic screening for occult gastrointestinal blood loss
}

\author{
F D Richard Hobbs, Russell C Cherry, John W L Fielding, Laurie Pike, Roger Holder
}

\begin{abstract}
Objective-To test patient compliance for faecal occult blood testing in suburban and inner city general practice.
\end{abstract}

Design-Prospective opportunistic trial using the Haemoccult test kit. Tests were offered during routine surgery attendance.

Setting-Three group general practices in Birmingham.

Subjects-All patients aged 40 years or older on the start date who routinely attended surgery during two years.

Main outcome measures-Numbers of patients approached for testing and the numbers refusing, accepting, and returning the test kits.

Results-Only $26 \cdot 3 \%(1230 / 4677)$ of the potential target population had been screened within the two years, although $988(39.3 \%)$ of the suburban practice target were screened. However, 55.7\% (1230/2207) of patients actually offered a test returned completed kits, with only $6 \%(133)$ refusing the kit. $683(61.6 \%)$ patients aged 50-69 returned kits, compared with $343(54.3 \%)$ aged 70 or over and $204(43.8 \%)$ aged 40-49. These differences were significant $(p<0 \cdot 001)$. Patients from the inner city practice were significantly less likely to be offered the test than those in suburban practice $(242(11 \cdot 2 \%) v 988(39.9 \%)$, $\mathrm{p}<0.001)$ and return the samples $(242(38.8 \%) v$ $988(62.4 \%), p<0.001)$. Patients from the inner city practice were also more likely to refuse the test (78 (12.5\%) v $55(3.5 \%), \mathrm{p}<0.001)$.

Conclusions-Opportunistic testing for occult faecal blood in asymptomatic patients was reasonably acceptable to patients, especially those in a suburban practice. If the test is shown to reduce mortality from colorectal cancer then formal screening would probably achieve acceptable target rates, especially among patients aged $50-69$, who represent the prime risk group.

\section{Introduction}

Colorectal cancer is the second commonest malignancy in Britain with 21000 new cases presenting each year. It accounts for 30-35 deaths per 100000 population. ${ }^{2}$ A practice of 6000 patients therefore might expect to see two deaths from this disease each year. The five year survival rate of colorectal cancer with all stages combined is $30 \%$. $^{3}$ Patients presenting with Dukes's A disease can expect a five year survival rate of $85 \%$, but this subgroup accounts for under $13 \%$ of those presenting with symptoms. ${ }^{4}$

The feasibility of screening for colorectal cancer by faecal occult blood testing in the community (mostly with the Haemoccult II test kit) has been studied..$^{5-9}$ An increase in detection of early stage disease has been shown, with $52 \%$ of tumours being Dukes's stage A. Such a shift in presentation might be expected to improve the five year survival.
The Haemoccult II test (Smith Kline Beckman, Derby) has a high specificity of $97 \%^{10}$ but poor sensitivity with a false negative rate of about $25 \%$. This makes repeat testing mandatory, usually after two years. Rescreening has achieved a compliance rate of $85 \% .{ }^{1 "}$ The test kit is cheap, has a long shelf life, and is easy to analyse, requiring no special training. Delay between completing the test and analysis does not affect the results.

With the two year follow up, testing with the Haemoccult kit satisfies one of the Wilson criteria ${ }^{12}$ for screening, which presumes a reliable and sensitive test. These criteria also include patient acceptability, and take up of the test has been poor. Although the main priority for any screening procedure is to reduce mortality and improve morbidity, achieving good compliance from patients is also essential if the test is to be practicable and cost efficient. In an attempt to improve compliance, previous workers have recruited patients in various ways. Methods include invitations in the work place $^{13}$; by post with an educational letter ${ }^{14}$; and from the general practitioner ${ }^{15}{ }^{16}$ and have achieved compliance rates of $27 \%^{13} ; 47 \%^{14}$; and $57 \%$ (range $26-82 \%){ }^{16}$

We attempted to confirm that patient compliance would be acceptable when screening was offered opportunistically during routine consultation with general practitioners. We also tested whether acceptance rates differed between suburban and inner city practices and with sex and age of patients.

\section{Subjects and methods}

We approached five Birmingham practices in 1987 to take part in the study. All were urban group practices that were already taking part in a study of open access endoscopy for dyspepsia. Although all partners in the five practices initially agreed to take part, only three practices started screening patients. The two practices withdrew principally because of concerns over the ethics of screening asymptomatic patients and time constraints.

The practices which started recruitment served one suburban population (A with 7000 patients and four partners) and two inner city populations (B with 4500 patients and three partners, $C$ with 6000 patients and three partners). All were training practices with above average numbers of ancillary staff $(>1.25$ full time equivalent staff per principal).

The study population was all patients over the age of 40 who were registered with the practices on the start date. These patients were identified from the (then) Birmingham Family Practitioner Committee computer, and the lists were provided to the practice and transferred on to a personal computer at Queen Elizabeth Hospital.

The purposes of the study and the methods of stool collection were explained to all partners. Reception staff were expected to check the surgery appointment

Dr Hobbs.

BMI 1992;304:483-6 
lists each day and identify patients eligible for testing. On arrival, these patients were handed a short information sheet about the proposed screening to be read while waiting. At an appropriate point during the subsequent consultation, the doctor or practice nurse provided further explanation and instruction on sample collection. Patients were then invited to take part and supplied with a three day Haemoccult test kit and instruction leaflet. Patients were required to collect two small samples of stool from different parts of a single motion, using a cardboard spatula. This was done over three consecutive days giving a total of six samples. The patient's choice about testing and action were recorded on a master list of study patients held at reception and on a small stick on label attached to the outside of the patient's clinical records.

Patients presenting with new symptoms of gastrointestinal disease were excluded from screening, as were those known to have existing gastrointestinal disease. Also excluded were those whose presenting complaint was of such seriousness that opportunistic invitation would be inappropriate. Names were recorded of patients who refused to be screened or whom the inviting staff thought to be too ill or incapable of completing the test.

Practices kept a record of the returned samples as patients handed them in. Completed kits were sent to Queen Elizabeth Hospital for analysis. The kit was developed with hydrogen peroxide and produced a blue colour if haemoglobin was present. The results were transferred to a personal computer, which generated both a result form to be sent to the practice and a letter informing the patient of the result.

Patients testing positive were invited by letter to visit their doctor for explanation and the test was then repeated over six days with dietary restrictions. Those who had negative results on six day testing were returned to standard follow up. Patients with positive results were seen by their general practitioner and a colonoscopy was arranged (within two weeks) at an open access clinic.

Progress was reviewed after two years of screening. The data were analysed with the generalised linear interactive modelling system (GLIM), ${ }^{17}$ which facilitates the analysis of frequency data that are affected by several factors simultaneously. Proportions or percentages were related to age, sex, and location of practice by a linear model similar to that used in analysis of variance. Proportions were initially transformed by a logit transformation and the error distribution was assumed to be binomial. The resulting analysis and significance tests showed the overall effect of each of the factors and also the joint (interactive) effect of combinations of factors.

\section{Results}

Compliance data was available from only two of the three practices that started screening. One inner city practice $(\mathrm{C})$, with a target population of 2788 patients, returned $493(17 \cdot 7 \%)$ completed kits, but had not kept reliable data on the number of kits that were supplied or refused. We therefore could not calculate response rates. Of the 493 kits returned, $15(3 \%)$ gave positive results, with four $(0.8 \%)$ patients having positive results on second testing. The analyses below refer to the remaining two practices (one inner city and one suburban). This examination remains valid since the purpose of the study was to test patient compliance with screening, which could be analysed in these two practices. The compliance of the practices is explored further in the discussion.

\section{UPTAKE OF TESTS}

Table I shows the crude numbers of patients in the total and target populations and the response to screening. After two years of opportunistic screening $1583(52 \cdot 8 \%)$ of patients from the suburban practice had been offered a test compared with $624(27 \%)$ from the inner city practice $(\mathrm{p}<0 \cdot 001)$. Overall, 2207 $(41.6 \%)$ patients in the target population had been approached.

The compliance of those offered the test was 988 $(62.4 \%)$ in the suburban practice and $242(38.8 \%)$ in inner city practice $(B)(\mathrm{p}<0.001)$ (table II). This difference was partially explained by a significantly higher refusal rate among inner city patients of 78 $(12.5 \%)$ refusals compared with $55(3.5 \%)$ in the suburban population $(\mathrm{p}<0 \cdot 001)$.

Overall, $1230(55 \cdot 7 \%)$ patients offered the test returned the samples, with $133(6 \%)$ refusing the kit (table II). In all, 59.3\% of those accepting the kit returned samples.

\section{COMPLIANCE OF PATIENTS BY AGE}

Highest compliance was obtained in patients aged

TABLE I - Response to offer of screening for faecal occult blood in two general practices

\begin{tabular}{|c|c|c|c|c|c|c|c|c|c|}
\hline & \multicolumn{2}{|c|}{$\begin{array}{c}\text { No (\%) of patients aged } \\
40-49 \text { years }\end{array}$} & \multicolumn{2}{|c|}{$\begin{array}{l}\text { No (\%) of patients aged } \\
50-69 \text { years }\end{array}$} & \multicolumn{2}{|c|}{$\begin{array}{c}\text { No }(\%) \text { of patients aged } \\
\geqslant 70 \text { years }\end{array}$} & \multicolumn{2}{|c|}{$\begin{array}{c}\text { No }(\%) \text { of patients aged } \\
\geqslant 40\end{array}$} & \multirow{2}{*}{$\begin{array}{c}\text { Combined } \\
\text { practices }\end{array}$} \\
\hline & Practice A & Practice B & Practice A & Practice B & Practice A & Practice B & Practice A & Practice B & \\
\hline \multicolumn{10}{|c|}{ Total population: } \\
\hline M & 322 & 331 & 610 & 527 & 394 & 225 & 1326 & 1083 & 2409 \\
\hline $\mathbf{F}$ & 315 & 259 & 682 & 484 & 675 & 481 & 1672 & 1224 & 2896 \\
\hline$M+F$ & & & & & & & 2998 & 2307 & 5305 \\
\hline \multicolumn{10}{|c|}{ Exclusions: } \\
\hline M & $32(9 \cdot 9)$ & $3(0 \cdot 9)$ & $36(5 \cdot 9)$ & $41(7 \cdot 8)$ & $85(21 \cdot 6)$ & $16(7 \cdot 1)$ & $153(11 \cdot 5)$ & $60(5 \cdot 5)$ & $213(8 \cdot 8)$ \\
\hline F & $19(6 \cdot 0)$ & $1(0 \cdot 4)$ & $56(8 \cdot 2)$ & $10(2 \cdot 1)$ & $259(38.4)$ & $70(14 \cdot 6)$ & $334(20 \cdot 0)$ & $81(6 \cdot 6)$ & $415(14 \cdot 3)$ \\
\hline$M+F$ & & & & & 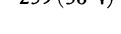 & $80(140)$ & $487(16 \cdot 2)$ & $141(6 \cdot 1)$ & $628(11 \cdot 8)$ \\
\hline \multicolumn{10}{|c|}{ Target population: } \\
\hline$M$ & $290(90 \cdot 1)$ & $328(99 \cdot 1)$ & $574(94 \cdot 1)$ & $486(92 \cdot 2)$ & $309(78 \cdot 4)$ & $209(92.9)$ & $1173(88 \cdot 5)$ & $1023(94 \cdot 5)$ & $2196(91 \cdot 2)$ \\
\hline $\mathrm{F}$ & $296(94)$ & $258(99 \cdot 6)$ & $626(91.8)$ & $474(97 \cdot 9)$ & $416(61 \cdot 6)$ & $411(85 \cdot 4)$ & $1338(80 \cdot 0)$ & $1143(93 \cdot 4)$ & $2481(85 \cdot 7)$ \\
\hline$M+F$ & & & & & & & $2511(83 \cdot 8)$ & $2166(93.9)$ & $4677(88 \cdot 2)$ \\
\hline \multicolumn{10}{|c|}{ Offered screening: } \\
\hline M & $129(40 \cdot 1)$ & $72(21 \cdot 8)$ & $363(59 \cdot 5)$ & $153(29 \cdot 0)$ & $206(52 \cdot 3)$ & $58(25 \cdot 8)$ & $698(52 \cdot 6)$ & $283(26 \cdot 1)$ & $981(40 \cdot 7)$ \\
\hline $\mathrm{F}$ & $185(58.7)$ & $80(30.9)$ & $433(63 \cdot 5)$ & $160(33 \cdot 1)$ & $267(39 \cdot 6)$ & $101(21 \cdot 0)$ & $885(52 \cdot 9)$ & $341(27.9)$ & $1226(42 \cdot 3)$ \\
\hline$M+F$ & & & & & & & $1583(52 \cdot 8)$ & $624(27 \cdot 0)$ & $2207(41 \cdot 6)$ \\
\hline \multicolumn{10}{|c|}{ Took test kits: } \\
\hline M & $124(38 \cdot 5)$ & $66(19 \cdot 9)$ & $351(57 \cdot 5)$ & $137(26 \cdot 0)$ & $195(49 \cdot 5)$ & $51(22 \cdot 7)$ & $670(50 \cdot 5)$ & $254(23 \cdot 5)$ & $924(38.4)$ \\
\hline $\mathrm{F}$ & $182(57 \cdot 8)$ & $65(25 \cdot 1)$ & $422(61.9)$ & $136(28 \cdot 1)$ & $254(37 \cdot 6)$ & $91(18 \cdot 9)$ & $858(51 \cdot 3)$ & $292(23.9)$ & $1150(39 \cdot 7)$ \\
\hline$M+F$ & & & & & & & $1528(51 \cdot 0)$ & $546(23 \cdot 7)$ & $2074(39 \cdot 1)$ \\
\hline \multicolumn{10}{|l|}{ Refused: } \\
\hline$M$ & $5(1 \cdot 6)$ & $6(1 \cdot 8)$ & $12(2 \cdot 0)$ & $16(3 \cdot 0)$ & $11(2 \cdot 8)$ & $7(3 \cdot 1)$ & $28(2 \cdot 1)$ & $29(2 \cdot 7)$ & $57(2 \cdot 4)$ \\
\hline $\mathrm{F}$ & $3(1 \cdot 0)$ & $15(5 \cdot 8)$ & $11(1 \cdot 6)$ & $24(5 \cdot 0)$ & $13(1.9)$ & $10(2 \cdot 1)$ & $27(1 \cdot 6)$ & $49(4 \cdot 0)$ & $76(2 \cdot 6)$ \\
\hline$M+F$ & & & & & & & $55(1.8)$ & $78(3 \cdot 4)$ & $133(2 \cdot 5)$ \\
\hline \multicolumn{10}{|c|}{ Returned samples: } \\
\hline$M$ & $57(17 \cdot 7)$ & $13(3.9)$ & $220(36 \cdot 1)$ & $69(13 \cdot 1)$ & $129(32 \cdot 7)$ & $15(6 \cdot 7)$ & $406(30 \cdot 6)$ & $97(9 \cdot 0)$ & $503(20.9)$ \\
\hline $\mathrm{F}$ & $106(33 \cdot 7)$ & $28(10.8)$ & $310(45 \cdot 5)$ & $84(17 \cdot 4)$ & $166(24 \cdot 6)$ & $33(6 \cdot 9)$ & $582(34 \cdot 8)$ & $145(11 \cdot 8)$ & $727(25 \cdot 1)$ \\
\hline$M+F$ & & & & & & & $988(33.0)$ & $242(10 \cdot 5)$ & $1230(23 \cdot 2)$ \\
\hline
\end{tabular}


TABLE II - Numbers (percentages) of patients complying with test according to age and practice

\begin{tabular}{|c|c|c|c|}
\hline Age group & Practice A & Practice B & Both practices \\
\hline \multicolumn{4}{|c|}{ 40-49 years: } \\
\hline \multicolumn{4}{|c|}{ Crude target population coverage: } \\
\hline M & $57 / 290(19 \cdot 7)$ & $13 / 328(4 \cdot 0)$ & $70 / 618(11 \cdot 3)$ \\
\hline F & $106 / 296(35 \cdot 8)$ & $28 / 258(10 \cdot 9)$ & $134 / 554(24 \cdot 2)$ \\
\hline$M+F$ & & & $204 / 1172(17 \cdot 4)$ \\
\hline \multicolumn{4}{|c|}{ Compliance of those offered test: } \\
\hline $\mathrm{M}$ & $57 / 129(44 \cdot 2)$ & $13 / 72(18 \cdot 1)$ & $70 / 201(34 \cdot 8)$ \\
\hline $\mathrm{F}$ & $106 / 185(57 \cdot 3)$ & $28 / 80(35 \cdot 0)$ & $134 / 265(50 \cdot 6)$ \\
\hline$M+F$ & & & $204 / 466(43 \cdot 8)$ \\
\hline \multicolumn{4}{|c|}{ Compliance of those accepting test: } \\
\hline$M$ & $57 / 124(46)$ & $13 / 66(19 \cdot 7)$ & $70 / 190(36 \cdot 8)$ \\
\hline $\mathrm{F}$ & $106 / 182(58 \cdot 2)$ & $28 / 65(43 \cdot 1)$ & $134 / 247(54 \cdot 3)$ \\
\hline$M+F$ & & & $204 / 437(46 \cdot 7)$ \\
\hline \multicolumn{4}{|c|}{ Refusal rate: } \\
\hline M & $5 / 129(3.9)$ & $6 / 72(8 \cdot 3)$ & $11 / 201(5 \cdot 5)$ \\
\hline F & $3 / 185(1 \cdot 6)$ & $15 / 80(18 \cdot 8)$ & $18 / 265(6 \cdot 8)$ \\
\hline $\mathrm{M}+\mathrm{F}$ & & & $29 / 466(7 \cdot 1)$ \\
\hline \multicolumn{4}{|c|}{ 50-69 years: } \\
\hline \multicolumn{4}{|c|}{ Crude target population coverage: } \\
\hline M & $220 / 574(38 \cdot 3)$ & $69 / 486(14 \cdot 2)$ & $289 / 1060(27 \cdot 3)$ \\
\hline $\mathrm{F}$ & $310 / 626(49 \cdot 5)$ & $84 / 474(17 \cdot 7)$ & $394 / 1100(35 \cdot 8)$ \\
\hline $\mathrm{M}+\mathrm{F}$ & & & $683 / 2160(31 \cdot 6)$ \\
\hline \multicolumn{4}{|c|}{ Compliance of those offered test: } \\
\hline M & $220 / 363(60 \cdot 6)$ & $69 / 153(45 \cdot 1)$ & $289 / 516(56 \cdot 0)$ \\
\hline F & $310 / 433(71 \cdot 6)$ & $84 / 160(52 \cdot 5)$ & $394 / 593(66.4)$ \\
\hline$M+F$ & & & $683 / 1109(61 \cdot 6)$ \\
\hline \multicolumn{4}{|c|}{ Compliance of those accepting test: } \\
\hline$M$ & $220 / 351(62 \cdot 7)$ & $69 / 137(50 \cdot 4)$ & $289 / 488(59 \cdot 2)$ \\
\hline $\mathrm{F}$ & $310 / 422(73 \cdot 5)$ & $84 / 136(61 \cdot 8)$ & $394 / 558(70 \cdot 6)$ \\
\hline$M+F$ & & & $683 / 1046(65 \cdot 3)$ \\
\hline \multicolumn{4}{|c|}{ Refusal rate: } \\
\hline M & $12 / 363(3 \cdot 3)$ & $16 / 153(10 \cdot 5)$ & $28 / 516(5 \cdot 4)$ \\
\hline $\mathrm{F}$ & $11 / 433(2 \cdot 5)$ & $24 / 160(15)$ & $35 / 593(5.9)$ \\
\hline$M+F$ & & & $63 / 1109(5 \cdot 7)$ \\
\hline \multicolumn{4}{|c|}{$\geqslant 70$ years: } \\
\hline \multicolumn{4}{|c|}{ Crude target population coverage: } \\
\hline M & $129 / 309(41 \cdot 7)$ & $15 / 209(7 \cdot 2)$ & $144 / 518(27 \cdot 8)$ \\
\hline $\mathrm{F}$ & $166 / 416(39.9)$ & $33 / 411(8 \cdot 0)$ & $199 / 827(24 \cdot 1)$ \\
\hline$M+F$ & & & $343 / 1345(25 \cdot 5)$ \\
\hline \multicolumn{4}{|c|}{ Compliance of those offered test: } \\
\hline M & $129 / 206(62 \cdot 6)$ & $15 / 58(25 \cdot 9)$ & $144 / 264(54 \cdot 5)$ \\
\hline F & $166 / 267(62 \cdot 2)$ & $33 / 101(32 \cdot 7)$ & $199 / 368(54 \cdot 1)$ \\
\hline$M+F$ & & & $343 / 632(54 \cdot 3)$ \\
\hline Compliar & & & \\
\hline $\mathrm{M}$ & $129 / 195(66 \cdot 2)$ & $15 / 51(29 \cdot 4)$ & $144 / 246(58 \cdot 5)$ \\
\hline $\mathbf{F}$ & $166 / 254(65.4)$ & $33 / 91(36 \cdot 3)$ & $199 / 345(57 \cdot 7)$ \\
\hline$M+F$ & & & $343 / 591(58.0)$ \\
\hline Refusal $\mathrm{r}$ & & & \\
\hline M & $11 / 206(5 \cdot 3)$ & $7 / 58(12 \cdot 1)$ & $18 / 264(6 \cdot 8)$ \\
\hline F & $13 / 267(4.9)$ & $10 / 101(9.9)$ & $23 / 368(6 \cdot 3)$ \\
\hline$M+F$ & & & $41 / 632(6 \cdot 5)$ \\
\hline All ages: & & & \\
\hline Crude tar & & & \\
\hline M & $406 / 1173(34 \cdot 6)$ & $97 / 1023(9 \cdot 5)$ & $503 / 2196(22 \cdot 9)$ \\
\hline $\mathrm{F}$ & $582 / 1338(43 \cdot 5)$ & $145 / 1143(12 \cdot 7)$ & $727 / 2481(29 \cdot 3)$ \\
\hline$M+F$ & $988 / 2511(39 \cdot 3)$ & $242 / 2166(11 \cdot 2)$ & $1230 / 4677(26 \cdot 3)$ \\
\hline Compliar & & & \\
\hline M & $406 / 698(58 \cdot 2)$ & $97 / 283(34 \cdot 3)$ & $503 / 981(5 \cdot 3)$ \\
\hline $\mathrm{F}$ & $582 / 885(65 \cdot 8)$ & $145 / 341(42 \cdot 5)$ & $727 / 1226(59 \cdot 3)$ \\
\hline$M+F$ & $988 / / 1583(62 \cdot 4)$ & $242 / 624(38 \cdot 8)$ & $1230 / 2207(55 \cdot 7)$ \\
\hline Compliar & & & \\
\hline $\mathrm{M}$ & $406 / 670(60 \cdot 6)$ & $97 / 254(38 \cdot 2)$ & $503 / 924(54 \cdot 4)$ \\
\hline $\mathrm{F}$ & $582 / 858(67 \cdot 8)$ & $145 / 292(49 \cdot 7)$ & $727 / 1150(63 \cdot 2)$ \\
\hline$M+F$ & $988 / 1528(64 \cdot 7)$ & $242 / 546(44 \cdot 3)$ & $1230 / 2074(59 \cdot 3)$ \\
\hline Refusal $r$ & & & \\
\hline M & $28 / 698(4 \cdot 0)$ & $29 / 283(10 \cdot 2)$ & $57 / 981(5 \cdot 8)$ \\
\hline $\mathrm{F}$ & $27 / 885(3 \cdot 1)$ & $49 / 341(14 \cdot 4)$ & $76 / 1226(6 \cdot 2)$ \\
\hline$M+F$ & $55 / 1583(3.5)$ & $78 / 624(12 \cdot 5)$ & $133 / 2207(6 \cdot 0)$ \\
\hline
\end{tabular}

50-69, with $683(61 \cdot 6 \%)$ patients returning tests, compared with $343(54 \cdot 3 \%)$ aged 70 or over and $204(43 \cdot 8 \%)$ of those aged 40-49 (table II). Significant differences between the age groups $(p<0.001)$ were evident in both practices. The combination of sex and age and practice and age further significantly explained variation in compliance $(p<0.05$ and $p<0.01$ respectively), with age having a more noticeable effect in the inner city practice and younger men (40-49) being generally less compliant.

Patients aged 50-69 were also most consistently approached for testing, with offers to $51 \cdot 3 \%$ (1109/2160) of the target population, compared with $47 \%(632 / 1345)$ of those aged 70 or over and $39.8 \%$ (466/1172) of those aged 40-49 $(\mathrm{p}<0.001)$. Again, significant variations with age were evident within each practice, with the combination of age and practice further significantly explaining the variation in the percentages $(p<0.01)$, the younger group $(40-49)$ being less often approached in the suburban practice.

There were no significant differences in refusal rates by age, although there was a slightly higher than expected refusal rate among patients aged over 70 in practice A.

\section{COMPLIANCE OF PATIENTS BY SEX}

There was more than twice the coverage of women aged $40-49$ than men with $46 \cdot 2 \%(265 / 574)$ women being offered a test compared with $30 \cdot 8 \%(201 / 653)$ men (table I). This trend was less evident in patients aged $50-69 \quad(50 \cdot 9 \%(593 / 1166)$ women $v \quad 45 \cdot 4 \%$ $(516 / 1137)$ men) and was reversed in those aged 70 or over $(31 \cdot 8 \%(368 / 1156)$ women $v 42 \cdot 6 \%(264 / 619)$ men).

Women were significantly more likely to return a kit than men: $727(59 \cdot 3 \%)$ women complied compared with $503(51.3 \%)$ men $(p>0.01)$ (table II). This difference was consistently seen by practice, with $65.8 \%$ of women and $58.2 \%$ of men complying in the suburban practice compared with $42 \cdot 5 \%$ of women and $34.3 \%$ of men in the inner city practice.

There was a gradual decrease in this difference between men and women with age, the difference being $15 \cdot 8 \%$ for those aged $40-49,10 \cdot 4 \%$ for those aged $50-69$, and $0.4 \%$ for those aged 70 or over. Women aged $40-49$ from the inner city practice refused the test more often than expected, but this did not reach significance.

\section{CASES DISCOVERED}

In all, 1854 patients from the three practices $(\mathrm{A}, \mathrm{B}$, C) completed Haemoccult test kits satisfactorily. Of these, $44(2 \cdot 37 \%)$ initially had positive results. On second testing $16(0.86 \%)$ had positive results and proceeded to colonoscopy. Six had colorectal cancer detected $(0 \cdot 32 \%)$ and five, polyps $(0 \cdot 27 \%)$.

\section{Discussion}

We failed to capture the enthusiasm of the practices and had we been testing the acceptability of the screen to general practices our conclusions would be more pessimistic. Two practices withdrew before screening started and the inner city practice recruited patients slowly during the two years, screening only $11 \cdot 2 \%$ of its target population. Practice $\mathrm{C}$ covered perhaps $35 \%$ (assuming that the kits returned represented around $50 \%$ of the kits supplied) of their target list and the suburban practice A achieved $39 \cdot 3 \%$ target population coverage. These are not encouraging figures. However, the coverage of opportunistic screens is likely to be variable $^{18}$ as they rely on the continued diligence of practice staff to approach patients over extended periods. Even simple screens have had poor uptake when performed opportunistically-for example, a study in Oxford showed an improvement in opportunistic blood screening from $31 \%$ to only $43 \%$ during $2 \frac{1}{2}$ years $^{19}$ and a $15 \%$ uptake of opportunistic cervical cytology testing was noted in a one year study performed before targets were introduced..$^{20}$

There were many reasons why two of the practices did not even start screening. One major factor was uncertainty among the partners that the tests were worth doing and the feeling that patients wouldn't want them. However, despite these same perceptions being voiced by the practices that did screen, their ultimate target population coverages were probably as good as could have been expected. Recruiting patients is certainly time consuming since explanation and demonstration of the test is likely to add one to two minutes to each consultation. Factors that are most likely to motivate practices to achieve good screening rates are evidence that the screen reduces mortality or morbidity; data on acceptability to patients; and some method of financial incentive (to fund development of systems to maximise coverage). Studies like the Nottingham trial are expected to help answer 
the first question and studies like ours the second.

The acceptability of the test to patients when offered opportunistically was better than expected. Only $6 \%$ of those offered the screen refused it, indeed the rate was only $3.5 \%$ in the suburban practice. The $12.5 \%$ refusal rate in the inner city practice was similar to the $11.5 \%$ rate of refusal for cervical smears in that practice (personal audit by FDRH).

Among patients who accepted the test, $59 \cdot 3 \%$ (range $44 \cdot 3 \%-62 \cdot 2 \%$ ) returned them. This is a good figure for an opportunistic screen, especially one which requires such cooperation by the patient. Even among elderly people (those aged 70 or over) the compliance on accepting the kit remained at $57.7 \%$ (range $33 \cdot 8 \%-65 \cdot 7 \%$ ) despite the technical difficulties they may have encountered in collecting the stool such as avoiding contact with water, using the small wooden spatula, and closing up the packets.

The best compliance rates were obtained from the 50-69 year age group. These people would be the most important to screen for occult blood loss as most colorectal tumours occur in this age band. Given current resource limits, screening would probably not be offered to people aged over 70 . Compliance on accepting the test among the 50-69 year olds was $65 \cdot 3 \%$ (range 56\%-68.9\%). These represented notably the best results in the inner city practice. The refusal rates of this age band were also the lowest at $5.4 \%$ and $5.9 \%$. Interestingly, this group were also the most completely covered with $31.6 \%$ of the target population reached (range 15.9\%-44.2\%) despite this group being expected to present infrequently to general practice (around $14 \%$ of $45-64$ year olds would be expected to consult each year). ${ }^{2}$

Another encouraging feature of the study was the reasonable compliance obtained from men, who would not normally expect to be approached for screening tests other than of blood pressure (and perhaps cholesterol). Overall, $54 \cdot 4 \%$ of men who accepted the kit returned a sample $(59 \cdot 2 \%$ of $50-69$ year old men).

Our main conclusion is that there was a reasonable uptake of opportunistic screening when conducted in motivated practices, especially among the group at most avoidable risk (those aged 50-69 years). Despite there being little to stimulate patient uptake (no government advertising or media information, no callrecall system) over $60 \%$ of patients in the 50-69 age band offered a test kit accepted and returned it. Even in the inner city practice $153(48.9 \%)$ of those offered the test $(56 \%$ of those who accepted it) complied. In the suburban practice $530(66 \cdot 6 \%)$ of those offered the test (68.6\% of those who accepted it) complied.

The practices were not effective in approaching patients. The two that did not start screening remained unconvinced about the ethics of screening with uncertain benefits for patients. This important question needs to be answered before scant resources are directed towards a screening programme which has yet to show a reduction in mortality and could increase morbidity through increased patient anxiety. ${ }^{22}{ }^{23}$ There is some reassurance about patient anxiety in the findings of Mant et al, who showed no excess stress in patients who had false positive results on the Haemoccult test compared with controls. ${ }^{24}$

If current studies confirm that faecal occult blood screening reduces mortality from bowel cancer a formal screening programme for middle aged patients should be considered, in addition to any opportunistic offers. A screening programme should achieve a greater patient coverage than in our study because of the use of call-recall schemes and a greater belief in the test by doctors increasing their motivation. Our study suggests that patients are likely to take up offers of testing for faecal occult blood, despite the basic technical skills required for adequate sample collection.

We thank the general practitioners and the staff of Greenbank, Bellevue, and Laurie Pike Medical Centres, who collected data; the surgical team and clerical staff under $\mathrm{Mr} \mathrm{J}$ Fielding at the Queen Elizabeth Hospital, who supplied and analysed the Haemoccult test kits; and Birmingham Family Practitioner Committee, which supplied the patient lists.

1 Kelly MH. Gastroenterology in treatment and prognosis in general practice. London: Heinemann, 1990

2 Weatherall DJ, Ledingham JGG, Warrell DA, eds. Oxford textbook of medicine. Vol 1. Oxford: Oxford University Press, 1983.

3 Gill PG, Morris PJ. The survival of patients with colorectal cancer treated in a regional hospital. Brf Surg 1978;65:17-20.

4 Holliday $\mathrm{H}$, Hardcastle JD. Delay in diagnosis and treatment of symptomatic colorectal cancer. Lancet 1979;i:309-11.

5 Hardcastle JD, Balfour TW, Amar SS. Screening for symptomless colorectal cancer by testing for occult blood in general practice. Lancet 1980;i:791-3.

6 Farrands PA, Hardcastle JD, Chamberlain J, Moss S. Factors affecting compliance with screening for colorectal cancer. Community Med 1984;6: $12-9$

7 Box V, Nichols S, Lallemand RC, Pearson P, Vakil PA. Haemoccult compliance rates and reasons for non-compliance. Public Health 1984;98: $16-25$.

8 Lallemand RC, Vakil PA, Box V. Screening for asymptomatic bowel cancer in general practice. $B M 7$ 1984;288:31-3.

9 Blalock S, DeVillis B, Sandler R. Participation in fecal occult blood screening: a critical review. Prev Med 1987;16:9-18.

$10 \mathrm{McCrae}$ FA, St John DJB. Relationship between patterns of bleeding and Haemoccult sensitivity in patients with colorectal cancers or adenomas. Gastroenterologv 1982;82:891-8.

11 Hardcastle JD, Thomas WM, Chamberlain J, Pye G, Sheffield J, James PD et al. Randomised, controlled trial of faecal occult blood screening for colorectal cancer. Lancet 1989;i:1160-4.

12 Wilson JMG, Junger G. The principles and practice of screening for disease. Geneva: World Health Organisation, 1968. (WHO public health papers 34)

13 Silma A, Mitchell P. Attitudes of non participants in an occupation based programme of screening for colorectal cancer. Community Med 1984;6:8-11.

14 Hardcastle JD, Farrands PA, Balfour TW, Chamberlain J, Amar SS, Sheldon MG. Controlled trial of faecal occult blood testing in the detection of colorectal cancer. Lancet 1983; ii:1-4.

15 Farrands PA, Griffiths RL, Britton DC. A practical solution to the diagnosis and treatment of colorectal cancer. Lancet 1981;i:1231.

16 Nichols S, Koch F, Lallemand RC, Heald RJ, Izzard L, Machin D, et al. Randomised trial of compliance with screening for colorectal cancer. $B M \mathcal{J}$ 1986;293:107-10.

17 Payne C, ed. The GLIM system Release 3.77 Manual. 2nd ed. Oxford NAG: 1987.

18 Mant D, Fowler G. Health checks for adults. BMJ 1990;300:1318-20.

19 Fullard E, Fowler G, Gray M. Promoting prevention in primary care: controlled trial of low technology, low cost approach. BMf 1987;294: $1080-2$

20 Pierce E, Lundy S, Palomisamy A, Winning S, King J. Prospective randomised controlled trial of methods of call and recall for cervical cytology rcreening.

21 Office of Health Economics. Compendium of health statistics. 7th ed. London: HMSO, 1989.

22 Stoate H. Can health screening damage your health? $\mathcal{I} R$ Coll Gen Pract 1989:39:193-5.

23 Love $R$, Camilli A. The value of screening. Lancet 1981;48:489-94.

24 Mant D, Fitzpatrick R, Hogg A, Fuller A, Farmer A, Verne J, et al. Experiences of patients with false positive results from colorectal cancer screening. Br $\mathcal{F}$ Gen Pract 1990;40:423-5.

(Accepted 30 Octoher 1991) 